\title{
A Novel Method of Speed Control for SRM using Pi Controller and Fuzzy Logic
}

\author{
Mrs. Sindhanai Arasi.C \\ Assistant Professor, Electrical and Electronics Engineering, Apollo Engineering college, Chennai
}

\begin{abstract}
The problem of Closed loop speed control and controller design of Switched Reluctance Motor is a topic of research interest in recent years. In this paper a simple speed control scheme for switched reluctance motor using microcontroller is proposed. This scheme is based on PI control algorithm. Firstly the simulation of the proposed speed controller scheme is executed using Matlab 7.0. Secondly the performance of the machine is analyzed. Finally implementation of the proposed controller is performed using PI controller, 18F2550.
\end{abstract}

Keywords: Closed loop, Switched Reluctance Motor, Matlab 7.0., PI control algorithm.

\section{INTRODUCTION}

The switched reluctance motor is a doubly salient machine with independent phase winding on stator and a solid laminated rotor. Due to its attractive features of high efficiency, high power density, low maintenance cost, switched reluctance motor is widely used in high performance servo applications. It is essential to design a high performance digital controller for switched reluctance machine to get optimum performance. This paper deals with the development of speed control scheme for switched reluctance motor using microcontroller. This method uses PI control algorithm. The simulation of the proposed speed controller scheme is executed using Matlab/Simulink. Section II deals with Switched Reluctance Motor specifications chosen for the development of simulink model. Section III deals with the Simulation using Matlab and results. Section IV deals with hardware implementation.

\section{SWITCHED RELUCTANCE MOTOR}

SRM is an electric motor in which the torque is produced by the tendency of its moveable part shifting to a position where the inductance of the excited winding is maximized. The cross-sectional view of a 8/6 SRM is shown in Fig 1. Both stator and rotor of the SRM has salient poles, but no winding on the rotor. The number of poles on the stator is usually unequal to the number on the rotor to avoid the eventuality of the rotor being in a state of producing no initial torque, which occurs when all the rotor poles are, locked in with the stator poles. The winding on the stator is wound on the diametrically opposite poles and connected in Series or parallel to form an electrically separate circuit called a phase. The rotor tries to move to a position of minimum reluctance by aligning itself with the stator magnetic field when the stator windings are excited.

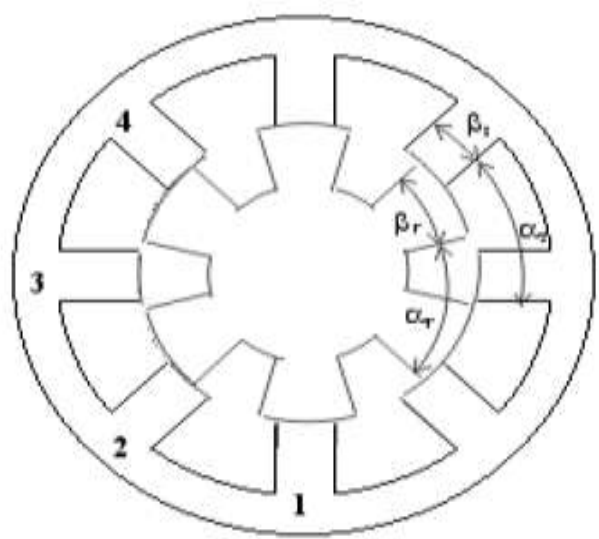

Fig1.Cross-section of a 8/6 pole 4-phase SRM 
Thus, by exciting the stator phase windings of the motor in a particular sequence and consequently, controlling the stepping magnetic field, we can control the movement of the rotor.

The machine specification:

Iinput voltage 230 volts

No. of turns 155

Rotor pole arc $30^{\circ}$

Stator pole arc $22.5^{\circ}$

maximum current $3 \mathrm{Amps}$

No. of stator poles 8

No. of rotor poles 6

\section{SIMULATION USING MATLAB}

The Switched Reluctance Machine is mathematically modeled in Matlab using the voltage Equation.

$$
\mathrm{V}=\mathrm{RI}+\frac{\mathrm{d} \Psi}{\mathrm{dt}}
$$

Where $\mathrm{V}$ is the terminal voltage, $\mathrm{I}$ is the phase current, $\mathrm{R}$ is the winding resistance and $\psi$ is the flux linked in the winding.

$$
\Psi(\theta, \mathrm{I})=\mathrm{L}(\theta) \mathrm{I}
$$

Where $\mathrm{L}$ is the phase Inductance and $\theta$ is the rotor position.

Neglecting the effect of saturation the torque Equation becomes

$$
\begin{aligned}
& \mathrm{T}=\frac{1}{2} \mathrm{I}^{2} \frac{\mathrm{dL}}{\mathrm{d} \theta} \\
& \mathrm{J} \frac{\mathrm{d} \omega}{\mathrm{dt}}=\mathrm{T}-\mathrm{T}_{\mathrm{L}}-\mathrm{J} \omega
\end{aligned}
$$

$\mathrm{J}$ is the moment of inertia, $\omega$ is speed in radians per second and $\mathrm{T}_{\mathrm{L}}$ is the load torque.

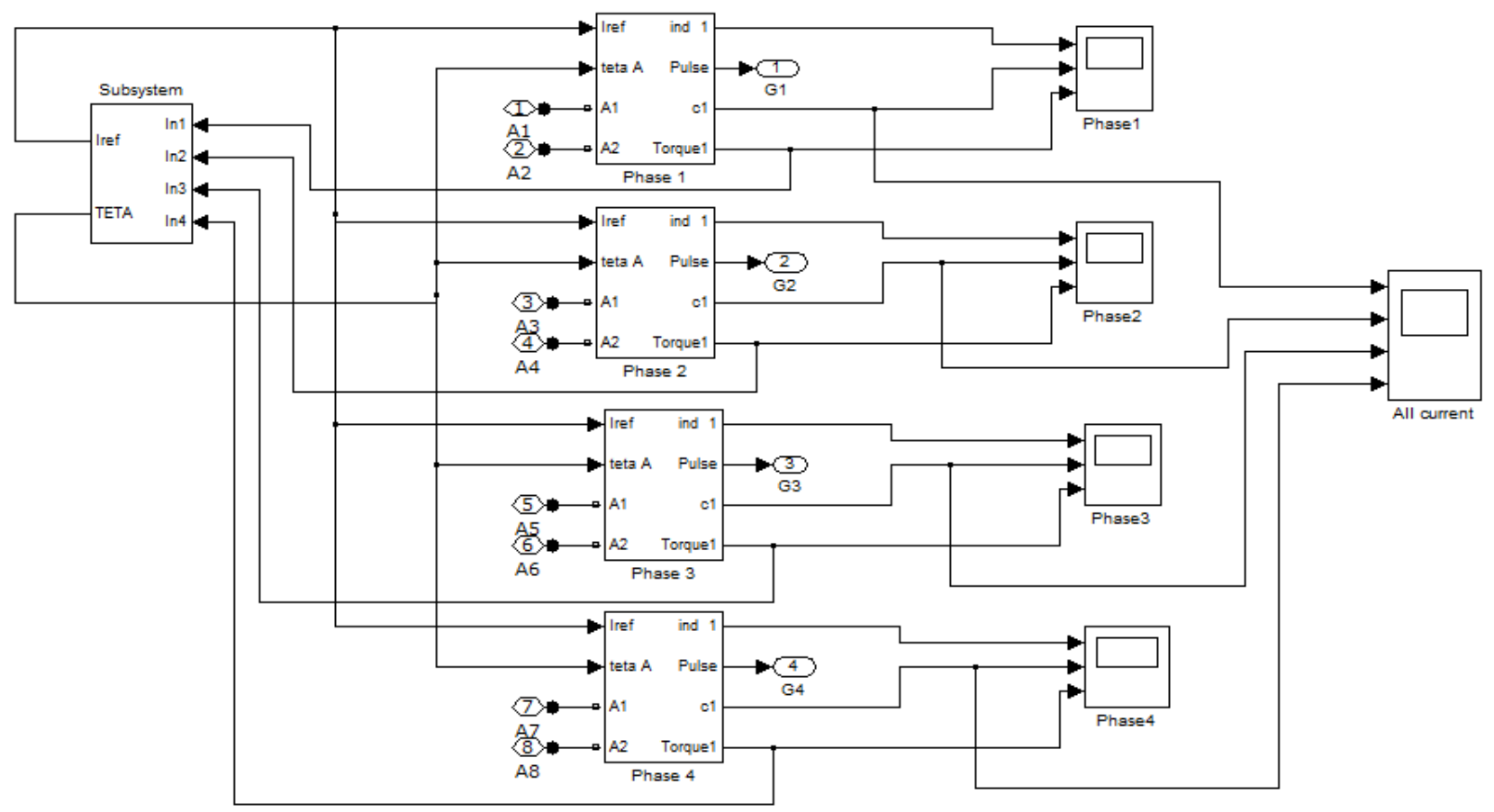

Fig.2 Matlab/Simulink diagram of SRM model 


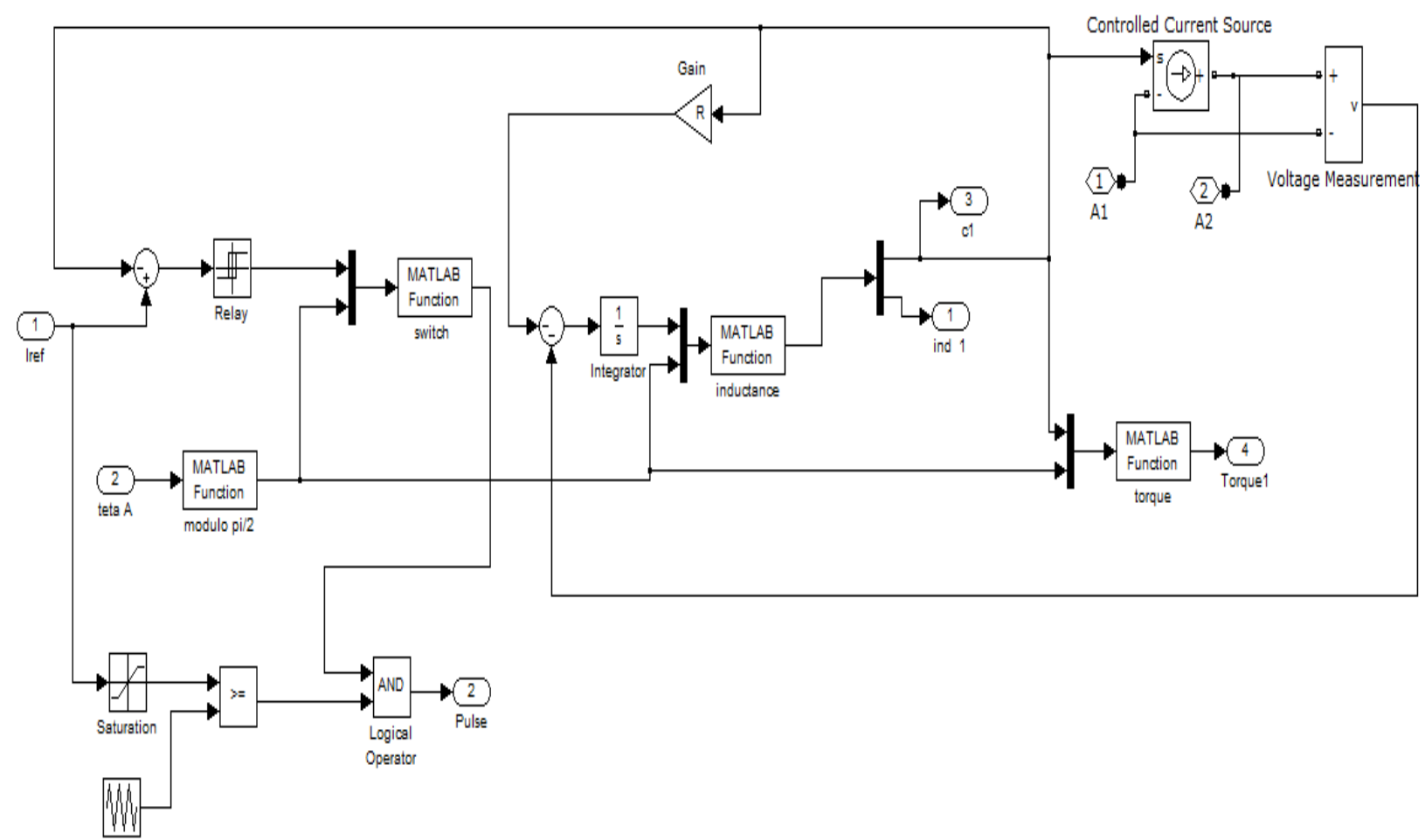

Fig.3 Single Phase Block diagram of SRM model

The Matlab/Simulink diagram of Switched Reluctance Machine model is shown in the fig.2. The fig.3 shows the contents of single phase block of SRM model. It contains four other blocks, each one associated with a specific Matlab function.

The block Switch permits to assure the power converter commutations at angles $\theta_{\text {on }}, \theta_{\text {off. Inductance block computes the }}$ current on the respective phase inductance according to rotor position $\theta$ and the phase flux $\Psi$. Torque block computes the torque produced in this phase according to the rotor position $\theta$ and the current value I. Asymmetrical bridge converter is used for simulation, and it is shown fig.4.

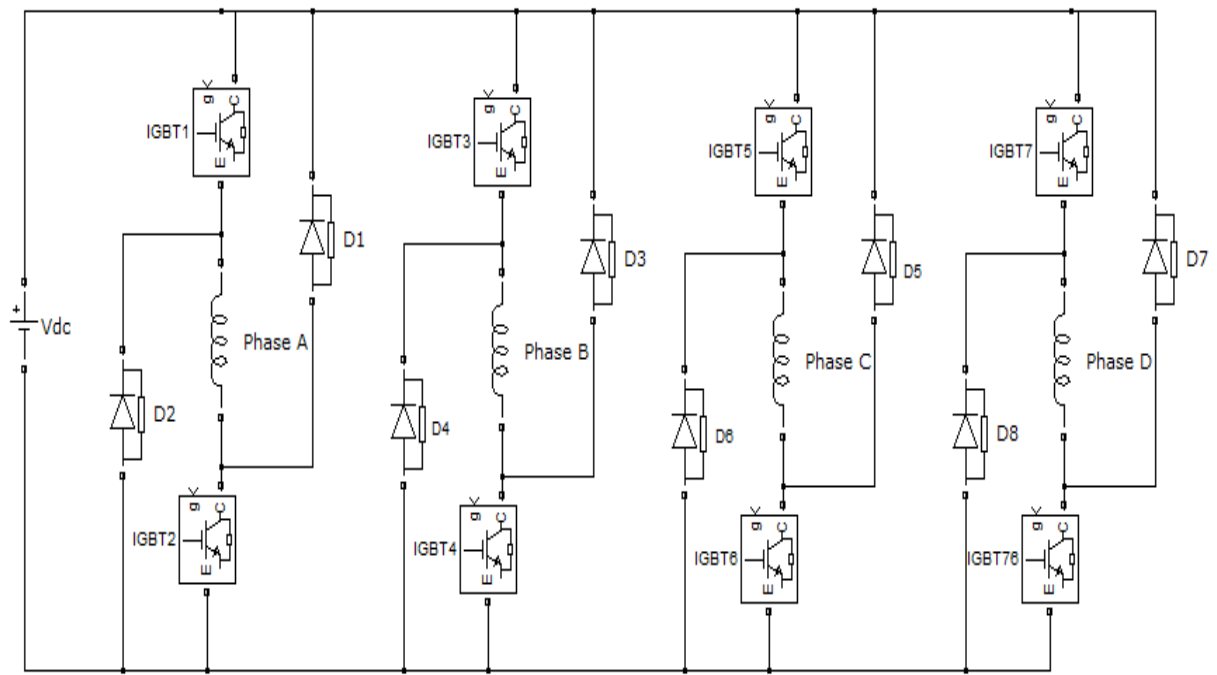

Fig.4 Asymmetric Bridge Converter 
International Journal of Advanced Research in Computer and Communication Engineering ISO 3297:2007 Certified

Vol. 6, Issue 4, April 2017

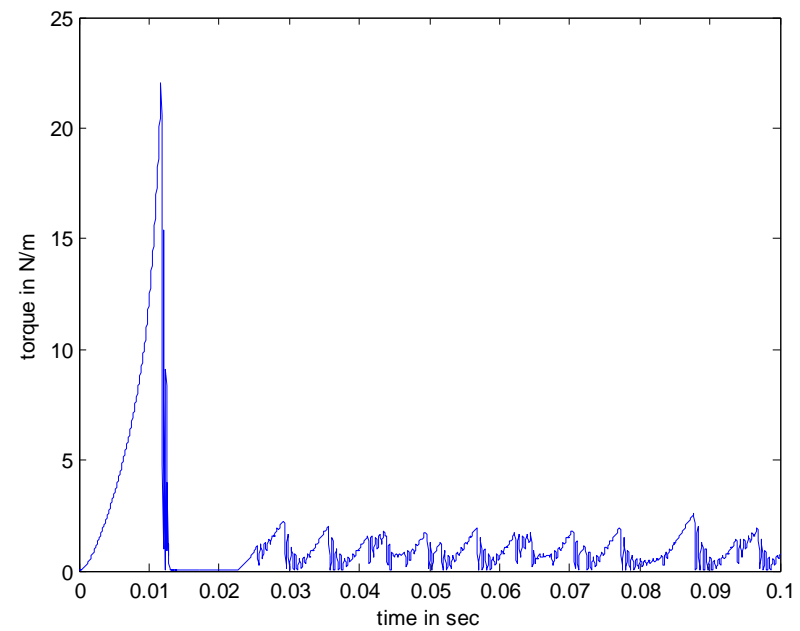

Fig.5 Torque Profile

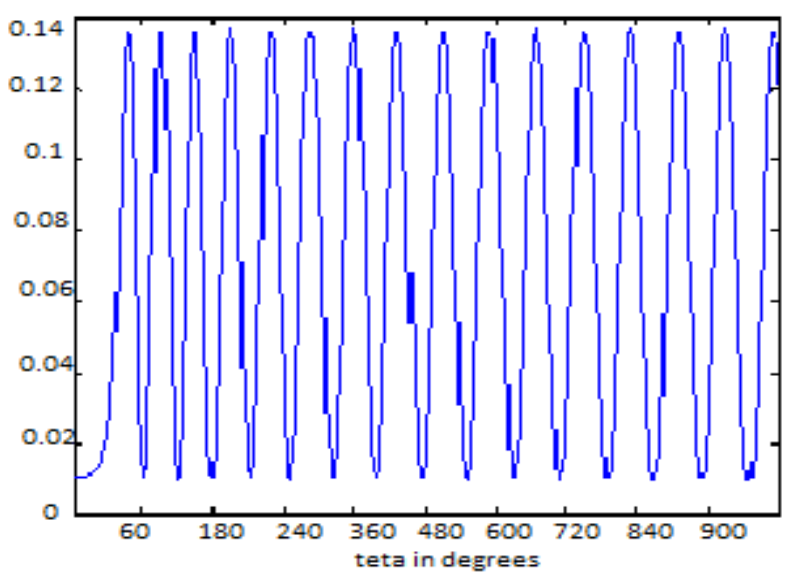

Fig.6 Inductance Profile

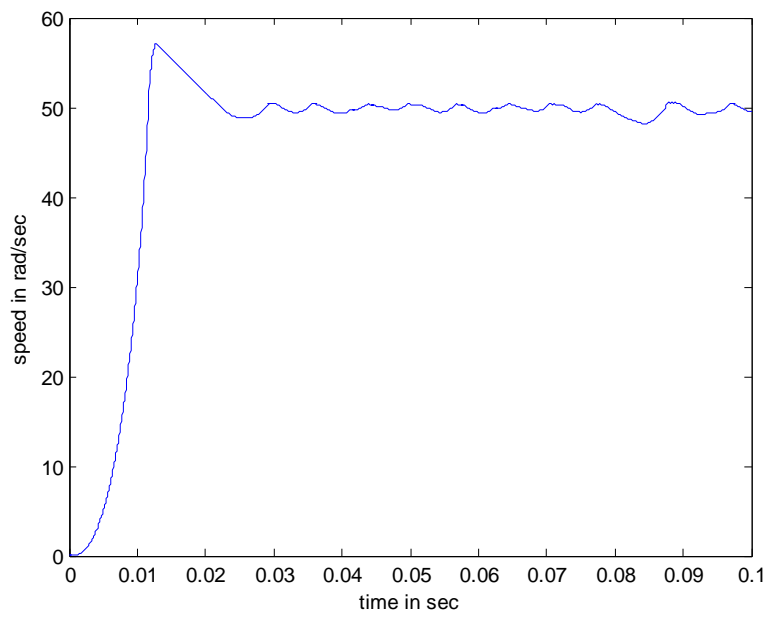

Fig.7 Speed response for 50rad/sec 


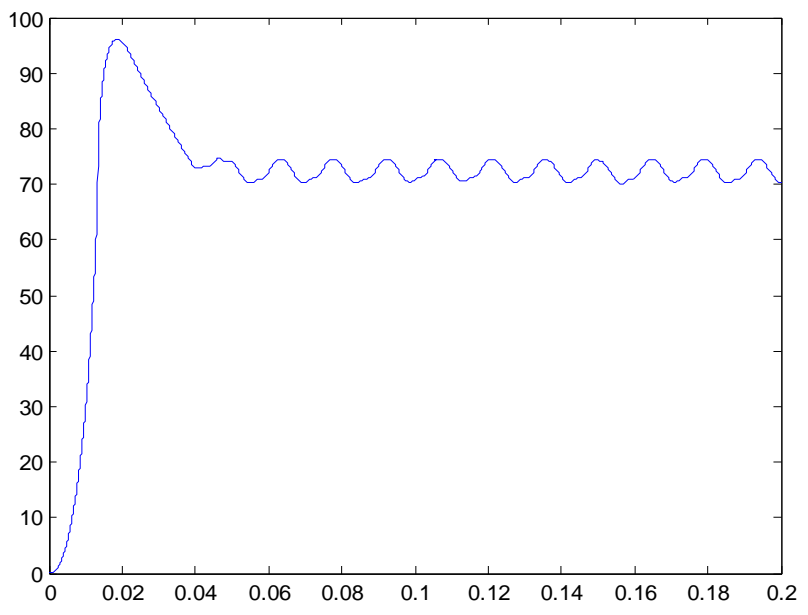

Fig.8 Speed response for $75 \mathrm{rad} / \mathrm{sec}$

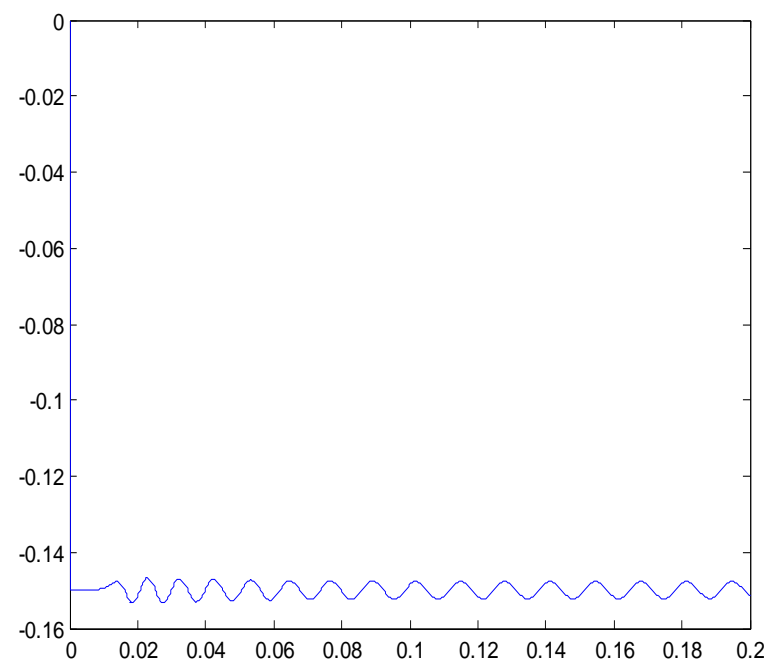

Fig.9 Phase current Profile

Inductance profile, Phase current variation, Torque Profile of the machine are shown in fig 5, 6, 9 respectively.

The speed response of switched reluctance motor for $50 \mathrm{rad} / \mathrm{sec}$ and $75 \mathrm{rad} / \mathrm{sec}$ are shown in fig. 7 and fig.8. From the speed response it is seen that speed control is achieved. The settling time is around $0.03 \mathrm{~s}$

\section{HARDWARE IMPLEMENTATION}

The block diagram of speed control of SRM drive is shown in fig.10. Rotor speed is converted to a voltage signal through tacho generator which then is filtered to provide $\omega r$, which then compared with its reference $\omega r^{*}$. The speed error signal is amplified and conditioned with the speed controller which normally is a proportional-plus-integral.

The output of this speed controller is a voltage signal proportional to current command signal I*. A current feedback signal in volts is compared with this command signal to generate a current error. This current error is processed through a PI controller to produce a command signal for the power converter 


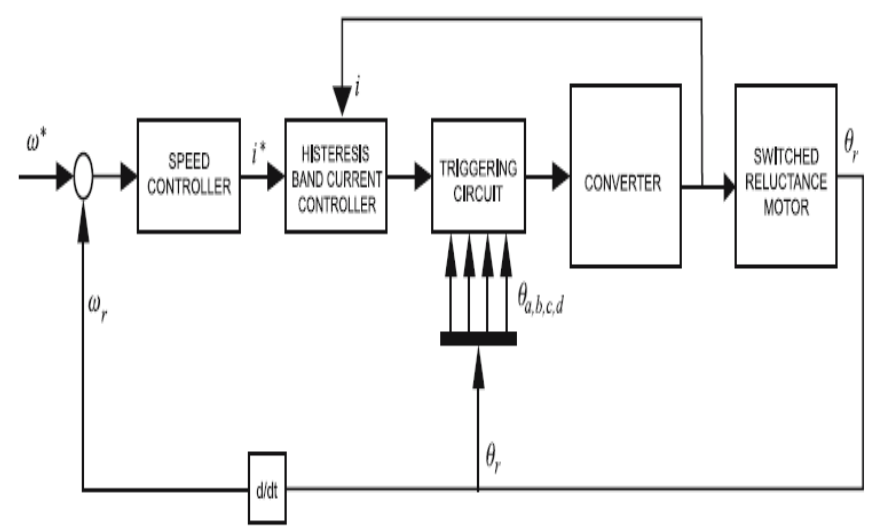

Fig.10 Block diagram of speed control of SRM

\section{CONCLUSION}

Switched Reluctance Motor is simulated using Matlab/Simulink environment. From the results it is seen that the proposed controller gives satisfactory performance. Experimental implementation is proposed using PIC microcontroller, $18 \mathrm{~F} 2550$.

\section{REFERENCES}

[1] R.Krishnan, "Switched Reluctance Motor Drives, Modeling, Simulation, Analysis, Design, and Applications", CRC Press.

[2] T.J.E.Miller," Switched Reluctance Motors and their Control" Magna Physics Publishing and Clarendon Press, Oxford, 1993

[3] R.Krishnan, R.Arumugam, "Design Procedure for Switched- Reluctance Motors" IEEE transactions on industry applications, vol. 24, no. 3, mayijune 1988 pp $456-460$

[4] Iqbal Husain and Syed A. Hossain, "Modeling, Simulation, and Control of Switched Reluctance Motor Drives", IEEE transactions on industrial electronics, vol. 52, no. 6, and December 2005 pp: $2447-2452$

[5] S.Paramasivam and Dr.R.Arumugam, "Ingenious Digital controller for switched Reluctance Motor Using Verilog”TENCON-2003 proceedings, pp143- 149.

[6] Kamaraj V, Aravind Vaithilingam C, "Modeling and simulation of switched reluctance machine (SRM) using MAGNET6.0", Volume 2, 19-22 Aug. 2001 Page(s):592 - 596 